\title{
Efficacy and Safety of X-incision with Inversed Morcellation in Holmium Laser Enucleation of the Prostate: Comparison to Conventional Morcellation
}

\author{
Dae Hyoung Park, Jong Bouk Lee, Chun Ha Hwang, Jong Hyun Yoon, Jung Hyun Jo, Tae Wook Jeong, Woong Na \\ Department of Urology, National Medical Center, Seoul, Korea
}

Corresponding Author:

Woong $\mathrm{Na}, \mathrm{MD}, \mathrm{PhD}$

Department of Urology, National

Medical Center, 245 Eulji-ro, Jung-gu,

Seoul 04564, Korea

E-mail:woong224@gmail.com

ORCID:

https://orcid.org/0000-0001-9871-8835

Received: August 16, 2019

Revised: September 13, 2019

Accepted: September 18, 2019
Background: Three-quarters of aged men experience lower urinary tract symptoms with benign prostate hypertrophy (BPH). Transurethral resection of the prostate (TURP) and holmium laser enucleation of the prostate (HoLEP) are standard endosurgical procedures in patients with BPH. Previous studies reported better results in patients undergoing HoLEP than in those undergoing TURP. Methods: This study compared the efficiency and safety of conventional morcellation and morcellation performed after $\mathrm{X}$-incision during enucleation, a newly added technique in HoLEP. Overall, 174 patients were selected as the final study population. The populations were stratified with respect to resected volumes. A t-test were used to compare the conventional morcellation and $\mathrm{X}$-incision procedure groups. Results: In morcellation times and rates, there were significant differences in stratified resected mass ( $\mathrm{g}$ ) between the groups. The results also showed a decreased incidence of bladder injury as a surgical complication. Conclusion: We believe morcellation performed after $\mathrm{X}$-incision procedure during enucleation is efficient and safe for older adults with $\mathrm{BPH}$.

Key Words: HoLEP, Morcellation, BPH, Enucleation

\section{INTRODUCTION}

Three-quarters of aged men experience low urinary tract symptoms (LUTS) with benign prostate hypertrophy (BPH). ${ }^{1)}$ These symptoms can be alleviated by medications; however, some patients with dysuria eventually undergo surgical treatment to prevent relative symptoms and diseases such as urinary retention, urinary tract infection (UTI), and urinary stones. ${ }^{2}$ In these cases, transurethral resection of the prostate (TURP) and holmium laser enucleation of the prostate (HoLEP) are considered standard endosurgical operations for patients with $\mathrm{BPH} .{ }^{3)}$

After Gilling et al. ${ }^{4)}$ first described HoLEP in 1995, its use has steadily increased. In the early days of laser prostatectomy, it was not useful due to serious complications such as long-term urinary obstruction and dysuria. However, with the development of sophisticated technologies, HoLEP is now used broadly and is recog- nized as an effective procedure on par with TURP while providing outstanding results in dissection, coagulation, and vaporization. ${ }^{4)}$ Moon et al. ${ }^{5)}$ reported less hemorrhage in HoLEP than that in TURP in prior BPH patients. In addition, compared to those who underwent TURP, patients who underwent HoLEP had outstanding results of the International Prostate Symptom Score (IPSS) at 12 months and maximum flow rates. Accordingly, there has been a paradigm shift to HoLEP as the primary surgery in modern $\mathrm{BPH}$, which alleviates LUTS and improves urodynamic study (UDS). ${ }^{6,7)}$

HoLEP with mechanical morcellation can be divided into two processes: gross tissue resection or enucleation and morcellation to extract enucleated prostatic tissue from the body. The early practice of leaving prostate tissue in the bladder after HoLRP caused problems. Techniques using transurethral grasper were considered but the enucleated prostatic tissue was sometimes too large to extract from the bladder. ${ }^{8}$ 

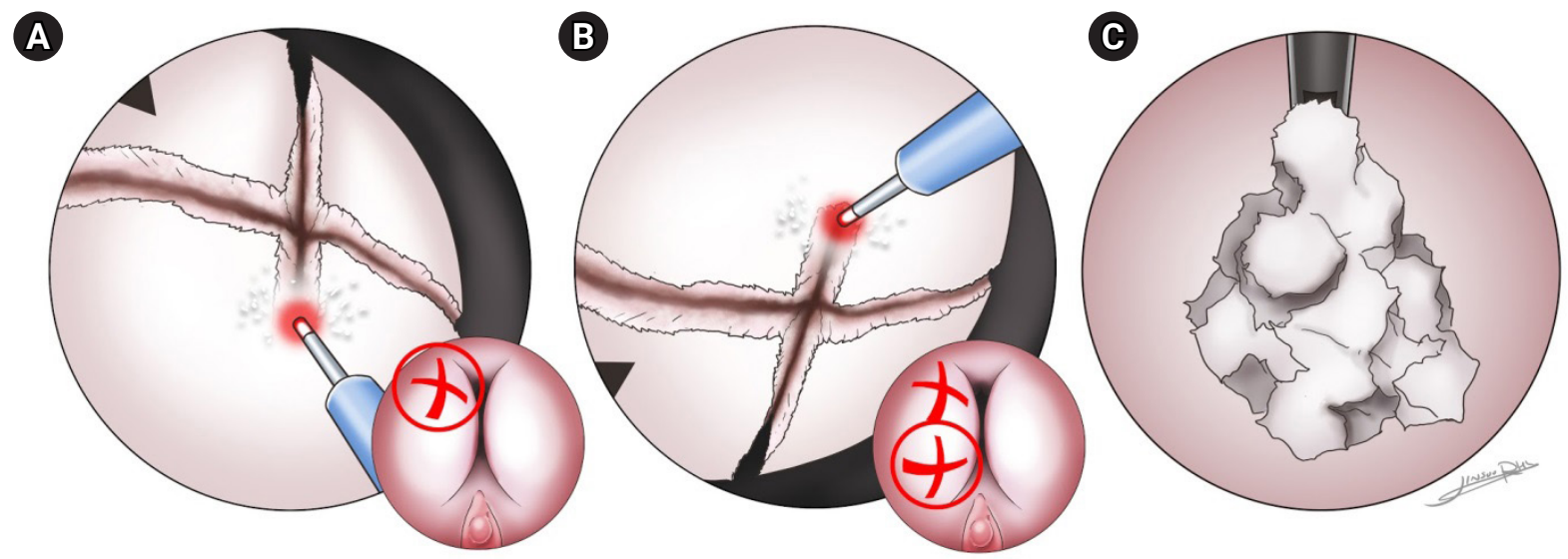

Fig. 1. X-incision in holmium laser enucleation of the prostate. (A, B) The enucleation partially resects the tissue in an X-shape with four parts per site. (C) The resected tissues are removed en masse during morcellation.

Since the development of Holmium: yttrium-aluminum-garnet (YAG) lasers, HoLEP was more practical by making enucleation of prostatic tissue easier. However, handling of the resected tissue remained a difficult task. Thanks to transurethral morcellators, large tissue masses are no longer a significant problem; however, major drawbacks like the potential for bladder injury and low suction efficacy remain. ${ }^{8-10)}$

To overcome these challenges, in 2012, Chen et al. ${ }^{11)}$ described an improved morcellation procedure during enucleation. This procedure included three stages: (1) roughening of the tissue surface during enucleation, (2) adoption of different methods according to volume sizes during morcellation, and (3) removal of prostatic tissue by laser or suction of the prostatic fossa. Evolution of this method roughens the surface during enucleation for better and easier morcellation. Enucleation partially resects the tissue into an $\mathrm{X}$-shape to form parts per site before the tissue is shredded. In addition, the resected tissue is massed together to be suctioned out simultaneously during morcellation (Fig. 1).

In the conventional method, morcellation of large and solid tissue requires significant time and additional resection of tissue in the bladder, which can lead to increased risks of bladder injury. Therefore, the present study compared the efficacy and safety of conventional morcellation and morcellation carried out after X-incision during enucleation, which is a newly-added technique in HoLEP.

\section{MATERIALS AND METHODS}

\section{Participants}

Patients with a medical history of prostate surgery, or repeated surgery, or surgery involving surgery for a kidney stone were excluded from this analysis.

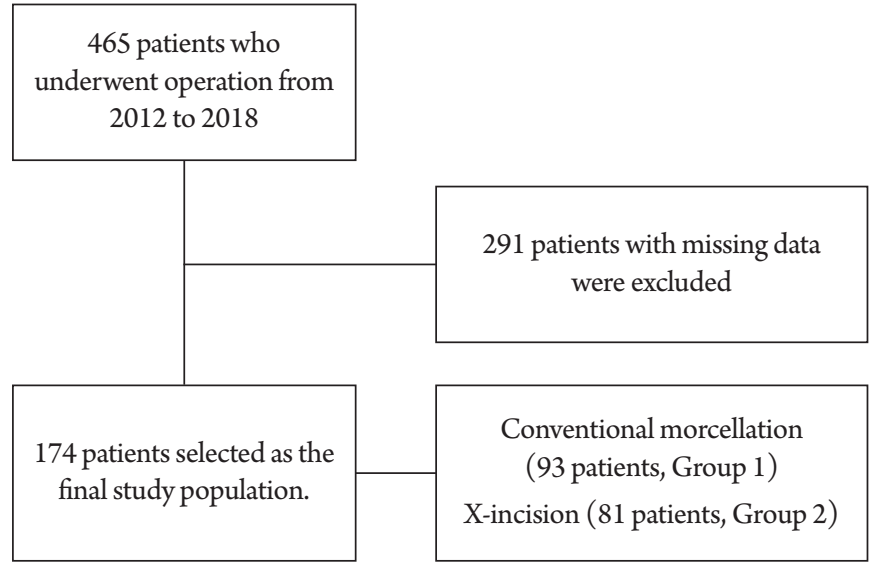

Fig. 2. Flowchart of the study population.

Data were collected from 465 patients who visited a general hospital in Seoul, Korea between January 2012 and December 2018. Among them, 291 patients with missing data (more than one variable) on prostate-specific antigen (PSA) level, operation time, morcellation time, transrectal ultrasound (TRUS), and resected weight were excluded. Therefore, a total of 174 patients (93 patients who underwent conventional morcellation and 81 who underwent $\mathrm{X}$-incision during enucleation) were included as the final study population (Fig. 2).

This study was approved by the Institutional Review Board of the National Medical Center (No. H-1901-098-002), which waived the requirement for written informed consent.

\section{Equipment and Procedure}

Morcellation was performed using a 26-Fr nephroscope and morcellator (VersaCut Morcellator; Lumenis Inc., Yokneam, Israel) 
from 80 to 100 W. A VersaPulse power holmium laser was used for prostate adenoma enucleation with a 26-Fr resectoscope (Karl Storz, El Segundo, CA, USA). The operator performed an X-incision before enucleation to make the prostate adenoma rougher and more resistant. If bleeding occurred, the operator performed dissection and coagulation. The enucleated prostatic tissue was cut into four pieces with one X-shaped incision per site range. The scope of the prostate within each site range was defined as the middle-sized lobe, and the operator performed X-incisions while sizing the prostatic tissue by $1 \times 1 \mathrm{~cm}$ roughly at a good distance of resecting the tissue with laser. For example, if one site of the lobe area measured $2 \times 2 \mathrm{~cm}, \mathrm{X}$-incisions were performed for four parts. Each incision required 3-4 seconds to perform; thus, in total, an average of 60 seconds was required per lobe site.

Normally, four X-incisions were required to roughen the surface. While the incisions were not intended to completely separate the resected tissues, this did occasionally occur. The tissue was then completely dissected until it remained attached to the bladder neck in a mushroom shape. Tissue removal was performed by retrograde morcellation. Every operation was performed by one operator with experience with more than 500 procedures.

\section{Statistical Analysis}

IBM SPSS Statistics version 19.0 for Windows (IBM Corp., Armonk, NY, USA) was used for statistical analysis. Descriptive statistics were determined for baseline characteristics such as age and prostate volume during TRUS. The conventional morcellation and $\mathrm{X}$-incision procedure group were also compared, with patients who did not undergo $\mathrm{X}$-incision designated as group 1 and those who underwent $\mathrm{X}$-incisions designated as group 2. Statistical analysis included t-tests, with $\mathrm{p}$-values less than 0.05 considered significant. To remove bias in the t-tests, the populations were stratified by resected mass ( $<20,21-40,41-60$, and $>61 \mathrm{~g})$.

\section{RESULTS}

This study included 174 patients with a mean age of $71.5 \pm 7.3$ years. Two patients had missing PSA data. Except for these two patients, the mean PSA level was $6.7 \pm 12.7 \mathrm{ng} / \mathrm{mL}$. The mean TRUS volume $(\mathrm{mL})$ was $56.4 \pm 27.9 \mathrm{~mL}$. The mean morcellation time and resected mass were $271.7 \pm 176.8$ seconds and $24.9 \pm 23.3 \mathrm{~g}$, respectively (Table 1 ). Group 1 included 93 patients with a mean age of $71.9 \pm 7.7$ years and mean PSA of $5.8 \pm 12.2 \mathrm{ng} / \mathrm{mL}$ except for one participant with missing PSA values. The mean TRUS volume was $53.0 \pm 26.3 \mathrm{~mL}$ and the mean morcellation time and resected mass were $286.1 \pm 196.2$ seconds and $19.9 \pm 19.4 \mathrm{~g}$, respectively. Group 2 included 81 patients with a mean age of $71.0 \pm 6.8$ years and mean PSA of $7.8 \pm 13.2 \mathrm{ng} / \mathrm{mL}$ except for one participant without PSA data. The mean TRUS volume was $60.3 \pm 29.4$ $\mathrm{mL}$ and the mean morcellation time and resected mass were $255.2 \pm 151.1$ seconds and $30.6 \pm 26.2$ g, respectively. There were statistically significant differences in resected mass and morcellation rate. The two groups were stratified according to resected mass for descriptive and t-test analyses.

In group 1 , the mean age was $70.9 \pm 6.9$ years for patients with resected masses less than $21 \mathrm{~g}, 71.7 \pm 8.1$ years for $21-40 \mathrm{~g}$, $75.1 \pm 5.9$ years for $41-60 \mathrm{~g}$, and $80.0 \pm 14.0$ years for $>61 \mathrm{~g}$. The mean morcellation time for patients with resected masses under $20,21-40,41-60$, and over $61 \mathrm{~g}$ were $187.4 \pm 83.0,379.6 \pm 63.6$, $551.6 \pm 126.0$, and $830.0 \pm 116.5$ seconds, respectively. The mean morcellation rate calculated as the resected mass per minute in each resected mass group were $3.7 \pm 1.6,4.3 \pm 0.5,5.2 \pm 1.1$, and $5.7 \pm 1.1 \mathrm{~g} / \mathrm{min}$, respectively. In group 2 , the mean age of patients with resected masses under 20, 21-40, 41-60, and over $61 \mathrm{~g}$ were $71.3 \pm 7.3,71.0 \pm 6.0,71.2 \pm 7.1$ and $70.0 \pm 6.8$ years, respectively. The mean morcellation times for these groups were $146.4 \pm 76.6$, $276.2 \pm 109.3,388.5 \pm 115.8$, and $470.4 \pm 93.0$ seconds, respectively. The mean morcellation rates were $5.9 \pm 4.3,7.1 \pm 3.5,8.5 \pm 3.3$, and $10.9 \pm 3.1 \mathrm{~g} / \mathrm{min}$, respectively. There were no significant differences in age and PSA values between the two groups for each resected amount. The difference in TRUS volume between the two groups was significant only for resected mass of 41-60 mL. The differences in morcellation time and rate were statistically significant for all stratified resected mass groups (Table 2).

\section{DISCUSSION}

This study evaluated the efficiency and safety of morcellation by merging the resected tissues as much as possible while making a rough surface during enucleation in HoLEP.

Group 2 underwent $\mathrm{X}$-incision during enucleation and showed reduced morcellation time and higher morcellation rate compared with the group that underwent conventional morcellation.

Lee et al. ${ }^{12)}$ reported that an inverse morcellation technique was

Table 1. Descriptive statistics of the baseline characteristics $(\mathrm{n}=174)$

\begin{tabular}{lc}
\hline & Value \\
\hline Age $(\mathrm{y})$ & $71.5 \pm 7.3$ \\
PSA $(\mathrm{ng} / \mathrm{mL})$ & $6.7 \pm 12.7$ \\
TRUS $(\mathrm{mL})$ & $56.4 \pm 27.9$ \\
Morcellation time $(\mathrm{s})$ & $271.7 \pm 176.8$ \\
Resected mass $(\mathrm{g})$ & $24.9 \pm 23.3$ \\
\hline
\end{tabular}

Values are presented as mean \pm standard deviation.

PSA, prostate-specific antigen; TRUS, transrectal ultrasonography. 


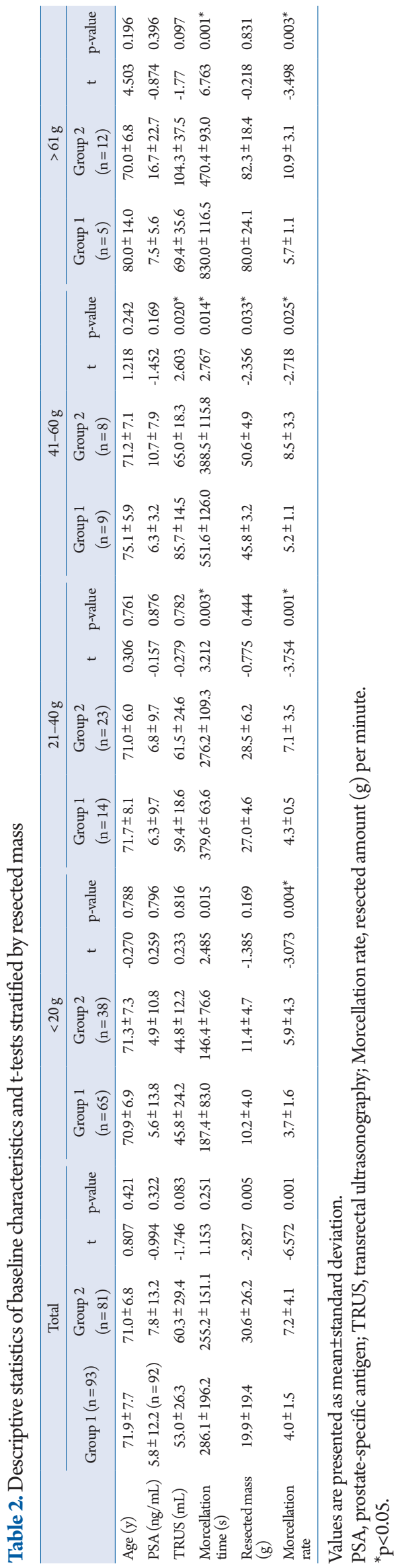


Table 3. Morcellation efficiency rates

\begin{tabular}{|c|c|c|}
\hline Study & Morcellation efficiency rate ( $\mathrm{g} / \mathrm{min})$ & Bladder injury cases (\%) \\
\hline Ishikawa et al. $^{15)}$ & 6.7 (inverse technique) & NA \\
\hline \multirow[t]{2}{*}{ Lee et al. ${ }^{12)}$} & $1.93 \pm 1.14$ (upward technique) & $11(13)$ \\
\hline & $4.06 \pm 0.95$ (inverse technique) & $2(2.5)$ \\
\hline Hurle et al. ${ }^{14)}$ & $2.3 \pm 1.5$ & $19(5.7)$ \\
\hline Kim et al. ${ }^{16)}$ & 4.3 & NA \\
\hline Rijo et al. ${ }^{13)}$ & $11.0(7.70-16.0)$ & $2(\mathrm{NA})$ \\
\hline
\end{tabular}

Values are presented as mean \pm standard deviation or median (min-max).

NA, not applicable.

safer and more efficient than the existing upward technique. This technique removes the glade between the blade and bladder wall with suction by placing the blade in the inverse position. Benefits such as improved morcellation efficiency and reducing bladder injury have been reported. Therefore, the present study applied the inverse technique based on the preceding research (Table 3). Rijo et al. ${ }^{13)}$ proved that morcellation using a mechanical morcellator is a safe and appropriate procedure to remove adenoma after enucleation, while Chen et al. ${ }^{11)}$ proposed three stages for more effective morcellation; namely roughening the gland surface, restriction of gland activity by contact with the morcellator blade, and loosening of hard and dense tissue.

The potential risks of morcellation include bladder injury and perforation. ${ }^{14)}$ Nonetheless, complications such as prostate capsule perforation during enucleation and bladder injury during morcellation have been dismissed as trivial. Rather, they have been considered the outcome of the learning curve. ${ }^{2)}$ This could be prevented to some extent by enlarging the bladder capacity before morcellation; however, it is restrictive and, to be certain, adenoma pretreatment and morcellation technique should be included. Hurle et al. ${ }^{14)}$ proposed that bladder injury could be alleviated only by improving the surgical technique while reporting a high rate of bladder injury of approximately $9 \%$ (bladder mucosal injury, $8.3 \%$; bladder perforation, $0.6 \%$ ) after morcellation.

Our study results showed increased morcellation rates and reduced incidences of complications such as bladder injury following $\mathrm{X}$-incisions to roughen resected prostatic tissue during enucleation. The results suggest that HoLEP combined with mechanical morcellation could replace TURP. This procedure could be considered as the primary operation for modern prostate surgery and $\mathrm{X}$-incisions during enucleation could be adopted for easier and safer morcellation. There are currently insufficient studies on easier, faster, and safer morcellation. Although techniques to roughen the gland surface have been proposed, large-scale studies are scarce.

The present study could not exclude the possibility of author bias as the procedures were executed by a single operator. The study did not include patients who underwent HoLEP from 2009 to 2011 and included only patients who underwent surgery after 2012, thus reducing the possibility of a learning curve. However, as this study was not performed under the same circumstances, operator bias cannot be excluded.

In conclusion, morcellation performed after the $\mathrm{X}$-incision procedure during enucleation as a newly adopted technique during HoLEP operation was efficient and safe; however, more case studies and research on this procedure are required.

\section{CONFLICT OF INTEREST DISCLOSURES}

The researchers claim no conflicts of interest.

\section{REFERENCES}

1. Boeri L, Capogrosso P, Ventimiglia E, Fontana M, Sampogna G, Zanetti SP, et al. Clinical comparison of holmium laser enucleation of the prostate and bipolar transurethral enucleation of the prostate in patients under either anticoagulation or antiplatelet therapy. Eur Urol Focus 2019 Mar 11 [Epub]. http://doi. org/10.1016/j.euf.2019.03.002.

2. Kuo RL, Paterson RF, Siqueira TM Jr, Watkins SL, Simmons GR, Steele RE, et al. Holmium laser enucleation of the prostate: morbidity in a series of 206 patients. Urology 2003;62:59-63.

3. Pushkar P, Taneja R, Agarwal A. A prospective study to compare changes in male sexual function following holmium laser enucleation of prostate versus transurethral resection of prostate. Urol Ann 2019; 11:27-32.

4. Gilling PJ, Cass CB, Malcolm AR, Fraundorfer MR. Combination holmium and Nd:YAG laser ablation of the prostate: initial clinical experience. J Endourol 1995;9:151-3.

5. Moon KY, Kim DY, Yoon JH, Na W, Lee JB. Outcomes of the holmium laser enucleation of the prostate for patients with prior benign prostatic hyperplasia surgery. J Korean Geriatr Soc 2014;18:199-204. 
6. Yin L, Teng J, Huang CJ, Zhang X, Xu D. Holmium laser enucleation of the prostate versus transurethral resection of the prostate: a systematic review and meta-analysis of randomized controlled trials. J Endourol 2013;27:604-11.

7. Aho TF. Holmium laser enucleation of the prostate: a paradigm shift in benign prostatic hyperplasia surgery. Ther Adv Urol 2013;5:245-53.

8. Hochreiter WW, Thalmann GN, Burkhard FC, Studer UE. Holmium laser enucleation of the prostate combined with electrocautery resection: the mushroom technique. J Urol 2002;168(4 Pt 1):1470-4.

9. Ahyai SA, Lehrich K, Kuntz RM. Holmium laser enucleation versus transurethral resection of the prostate: 3-year follow-up results of a randomized clinical trial. Eur Urol 2007;52:1456-63.

10. Gilling PJ, Kennett K, Das AK, Thompson D, Fraundorfer MR. Holmium laser enucleation of the prostate (HoLEP) combined with transurethral tissue morcellation: an update on the early clinical experience. J Endourol 1998;12:457-9.

11. Chen $\mathrm{Q}_{2}$ Chen YB, Wang Z, Peng YB, Zheng DC, Cai ZK, et al. An improved morcellation procedure for holmium laser enucle- ation of the prostate. J Endourol 2012;26:1625-8.

12. Lee SH, Choi JI, Moon KY, Na W, Lee JB. Holmium laser enucleation of the prostate: modified morcellation technique and results. Korean J Urol 2012;53:779-84.

13. Rijo E, Misrai V, Gomez-Sancha F. Recommendations for safe and efficient morcellation after endoscopic enucleation of the prostate (EEP). Eur Urol Suppl 2018;17:e1980.

14. Hurle R, Vavassori I, Piccinelli A, Manzetti A, Valenti S, Vismara A. Holmium laser enucleation of the prostate combined with mechanical morcellation in 155 patients with benign prostatic hyperplasia. Urology 2002;60:449-53.

15. Ishikawa R, Shitara T, Wakatabe Y, Kubo S, Hirayama T, Fujita T, et al. Relationship between morcellation efficiency and enucleated tissue weight in holmium laser enucleation of the prostate (HoLEP) for patients with benign prostatic hyperplasia. Nihon Hinyokika Gakkai Zasshi 2011;102:675-8.

16. Kim SC, Matlaga BR, Kuo RL, Watkins SL, Kennett KM, Gilling PJ, et al. Holmium laser enucleation of the prostate: a comparison of efficiency measures at two institutions. J Endourol 2005; 19:555-8. 